\title{
The Impact of Direct-to-Consumer Pharmaceutical Advertising on Public Knowledge of Gastroesophageal Reflux Disease: A Study on Over-the-Counter Proton Pump Inhibitors
}

This article was published in the following Dove Press journal:

Patient Preference and Adherence

\author{
Maram AIShammari ${ }^{1}$ \\ Ghadah Assiri (D) \\ Mohammed \\ bin Buraykan' \\ Yasser Almogbel $\mathbb{D}^{2}$ \\ Azher Arafah 1,3 \\ Adel Bashatah (iD) 4 \\ Yazed AlRuthia (iD) 1,5 \\ 'Department of Clinical Pharmacy, \\ College of Pharmacy, King Saud \\ University, Riyadh, Saudi Arabia; \\ ${ }^{2}$ Department of Pharmacy Practice, \\ College of Pharmacy, Qassim University, \\ Buraidah, Saudi Arabia; ${ }^{3}$ Department of \\ Pharmacy Practice, College of Pharmacy, \\ AlMaarefa University, Riyadh, Saudi \\ Arabia; ${ }^{4}$ Department of Nursing \\ Education and Administration, College of \\ Nursing, King Saud University, Riyadh, \\ Saudi Arabia; ${ }^{5}$ Pharmacoeconomics \\ Research Unit, College of Pharmacy, King \\ Saud University, Riyadh, Saudi Arabia
}

Background: The use of direct-to-consumer advertising (DTCA) to promote sales of overthe-counter (OTC) pharmaceuticals used to manage common medical conditions, such as gastroesophageal reflux disease (GERD), is increasing. However, the educational value of these advertisements as well as the public perceptions of this type of advertising remain largely unknown among non-English speaking populations.

Objective: The aim of this study was to explore the public perceptions and educational value of a short motion graphic video documenting the lifestyle of person with GERD and presenting a brief introduction to the role of proton pump Inhibitors (PPIs) in relieving the symptoms.

Methods: This was a prospective quasi-experimental study in which a short mock advertising motion graphic video was shown to a sample of adult individuals in malls and shopping centers in different cities across Saudi Arabia. Participants were required to express their levels of agreement with six statements concerning their perceptions of DTCA of OTC drugs, and answer a quiz consisting of three questions and enquiries about their knowledge of GERD and the OTC drugs used in its treatment.

Results: Two hundred and ninety-five participants were involved in this study, the majority of whom were female (55.30\%). After watching the video, the percentages of participants who strongly agreed or agreed that DTCA is a credible source of information and encourages them to purchase the marketed drug have increased significantly $(P<0.05)$. With regard to the quiz, the percentages of participants with correct answers regarding the definition of GERD, knowledge of OTC drugs for GERD, and awareness of the common side effects of PPIs increased from $81.69 \%$ to $95.93 \%, 69.83 \%$ to $96.27 \%$, and $46.44 \%$ to $91.53 \%$, respectively $(P<0.0001)$.

Conclusion: DTCA of OTC drugs for GERD, particularly if the content complies with the regulatory requirements, can promote the public knowledge of the disease and treatment options.

Keywords: direct-to-consumer advertising, gastroesophageal reflux, proton pump inhibitors

\section{Introduction}

Direct-to-Consumer Advertising (DTCA) of pharmaceuticals, defined as "any presentation or promotion of the information of the prescribed medications in media to the general population", ${ }^{1}$ has gained increasing attention over the past two decades, enhancing consumer access to prescription drug information. Advertising of
Department of Clinical Pharmacy, College of Pharmacy, King Saud University, Riyadh, Saudi Arabia

Tel +996 I I 4677483

Fax $+966 \quad I 14677480$

Email yazeed@ksu.edu.sa 
pharmaceutical products began in the 18th century and by the 19th and 20th centuries was very common. ${ }^{2}$ However, at present, the United States and New Zealand are the only two countries that legally allow DTCA of prescription drugs. ${ }^{3}$ DTCA utilizes newspapers, periodicals, radio, television, magazines, and more recently, advanced technologies such as the Internet and smartphones. ${ }^{4}$ However, the content of DTCA on websites is not always regulated, increasing the likelihood of inaccurate or misinformation. ${ }^{4}$ Nevertheless, DTCA have had a positive impact on the relationship between patients and healthcare providers, facilitating communication and discussion regarding health conditions and treatment options. ${ }^{2,5}$ Moreover, this relationship has improved over time with the introduction of government policies aimed at regulating drug advertising. ${ }^{6}$

DTCA of prescription medications is a significant factor in shaping the health care market. Between 1993 and 2005, spending on DTCA by pharmaceutical companies increased from $\$ 166$ million to $\$ 4.2$ billion, ${ }^{6}$ reaching $\$ 4.5$ billion in $2009{ }^{7,8}$ In turn, drug manufacturers benefit directly from DTCA. ${ }^{9}$ For example, Schering-Plough invested $\$ 186$ million in promoting its antihistamine product Claritin (Loratadine), resulting in a swift rise in profits from resulting sales. ${ }^{10}$ The most commonly advertised drugs are those prescribed for allergies, obstetrics/ gynecology, and dermatological diseases, while less frequent are those related to diabetes, respiratory diseases, and cancer. $^{2}$

DTCA has also been found to be effective. For example, as shown in a study of patients living in Sacramento, California (USA), whereby advertised medications were more frequently requested than in Vancouver, Canada, where DTCA is not legal. ${ }^{11}$ Moreover, according to a CBS Health Watch, 66\% of drug consumers in central USA were able to recall a particular drug that was advertised through print, while $61 \%$ of consumers in the southern USA were able to recall a drug advertised on TV. ${ }^{2}$

It has been suggested that the recent expansion of DTCA is responsible for the increasing cost of prescription drugs, ${ }^{12}$ with the promotion of a single brand leading to improved sales of the entire therapeutic class. ${ }^{13}$ Advertising of prescribed medications could increase pricing due to the high cost of advertisements, ${ }^{2,7}$ or by generating increased demand. ${ }^{12,13}$ However, DTCA-driven increases in prescribed drugs does not bring additional benefits in terms of health outcomes. ${ }^{14}$ On the contrary, an alarming $17.8 \%$ of participants stopped their medication after learning about possible side effects from DTCA. ${ }^{15}$ On the other hand, other studies have pointed out the advantages of DTCA, suggesting that advertising increases patient adherence to a therapeutic plan, thereby improving health conditions. ${ }^{16-19}$ A survey conducted by the US Food and Drug Administration (FDA) indicated that DTCA increases consumer awareness and stimulates the search for further information on the advertised medication. ${ }^{18}$ Another survey distributed to 1445 subjects in western Saudi Arabia to explore the public perception of pharmaceutical advertising of OTC medications revealed mostly positive views on pharmaceutical advertisements and their role in education and raising public awareness about medications and their side effects. ${ }^{19}$ Moreover, it has also been suggested that advertisements targeted directly at the public improve health awareness and communication between patients and their healthcare providers. ${ }^{20}$

One of the most frequently advertised types of drug are those used in the treatment of gastroesophageal reflux disease (GERD). GERD is a common condition worldwide, including the Middle East, where its prevalence is estimated to range from $8.7 \%$ to $33.1 \% .{ }^{21}$ Typically, GERD is treated with over-the-counter (OTC) medications such as antacids (aluminum hydroxide/magnesium carbonate, calcium carbonate, and sodium bicarbonate), $\mathrm{H}-2$ receptor antagonists (H2RAs; eg, ranitidine, nizatidine, and famotidine), and Proton Pump Inhibitors (PPIs) (eg, pantoprazole, omeprazole, esomeprazole, lansoprazole). ${ }^{22}$ PPIs are considered the most effective class of drugs for the management of GERD, yielding higher endoscopic healing rates than other types of acid reducers. ${ }^{23,24}$ The objective of the present study was to explore the public perception of DTCA and its impact on public knowledge of GERD, the overall understanding of this disease, and the use of non-prescription PPIs among a sample of adults in Saudi Arabia.

\section{Methods}

\section{Study Design}

This investigation was designed as a quasi-experimental pretest-posttest study. Adult individuals, aged 18 years or older, without communication barriers (eg, dementia, cognitive disabilities, and deafness) were invited to participate. Potential participants were approached in malls and public parks in 11 cities across Saudi Arabia (Riyadh, Buraydah, Jeddah, Al-Madinah, Makkah, Abha, Dammam, Al-Jubail, Alkhobar, Jazan, and Albaha) between January and July 2019. After briefly explaining the purpose of the research, participants were asked to sign a written consent form specifying that the collected data would be 
anonymized to protect their confidentiality as well as affirming their right to withdraw from the study at any time.

\section{Intervention}

A short-animated video promoting the use of an OTC PPI for GERD was created to assess the impact of DTCA on the public perception of this form of advertising and general knowledge of GERD and PPIs. The video included a short story in colloquial Arabic language about a man with several risk factors for GERD (sedentary lifestyle, smoking, consumption of spicy food, lack of exercise) who went on to suffer a heartburn attack. A simple visual explanation of heartburn was also provided in the video. The man went to a pharmacy and asked the pharmacist about medications that could be used to alleviate his pain. The pharmacist explained different OTC treatments, including H2RA and PPIs, and after listing three examples recommended one PPI. The common side effects of PPIs were also explained and the man was advised by the pharmacist to use the medication for 14 days and visit his primary care physician if the symptoms were not resolved. The video concluded with the pharmacist encouraging the man to adopt various lifestyle changes that are proven to alleviate GERD symptoms, such as regular exercise, quitting smoking, and avoiding certain foods (spicy food, ginger, mint).

The video was reviewed by an ambulatory care clinical pharmacist and by health outcome researchers to check the validity of its content and avoid any marketing of a particular brand of PPI. The purpose of showing the video was not explicitly explained to the participants.

\section{Questionnaire Development}

A three-part questionnaire was also distributed to the participants, sections two and three of which were completed both before and after watching the video. The first part consisted of questions regarding the sociodemographic characteristics of the participants, the presence of medical conditions including GERD, and the use of any OTC medications or herbal products. Moreover, the health literacy of the participants was also assessed using the Arabic version of the Single Item Literacy Screener (SILS). ${ }^{25,26}$

The second section consisted of six statements that were created based on an extensive review of the literature. ${ }^{2-5,19}$ Participants were asked to strongly disagree, disagree, remain neutral, agree, or strongly agree with each of the following six statements:
1. DTCA is an informative tool in terms of explaining the benefits and harms of drugs.

2. DTCA is a credible source of information on OTC drugs.

3. If presented in an attractive and eye-catching way, DTCA may encourage me to purchase the marketed OTC drug.

4. If I liked a DTCA of a certain OTC drug, this may change my view about the drug.

5. My decision to buy an OTC drug is independent and not influenced by DTCA.

6. The more frequently I watch a DTCA about a certain pharmaceutical product, the more likely I am to buy that product.

The third section was a multiple choice quiz developed to assess participants' awareness and knowledge of the definition of GERD, OTC medications used in the management of GERD, and common side effects of PPIs. Each question included four possible answers of which only one was correct. The quiz was administered both before and after the presentation of the video. The questions and possible answers are listed in the Appendix.

\section{Sample Size and Data Collection}

Based on $\alpha=0.05, \beta=0.2$, power of 0.8 , and a medium effect size of Cohen's $\mathrm{w}=0.22$, the minimum sample size was estimated to be 266 individuals. However, taking into account the withdrawal of participants and missing data, the aim was recruitment of 300 subjects.

The questionnaire was pilot-tested among 20 participants in order to check its readability, resulting in only a few changes. Fourteen data collectors were involved in interviewing the participants after explaining the purpose of the study and obtaining written informed consent. Each data collector was given a written protocol to follow during the participant interview.

\section{Ethical Considerations}

No personal identifiers were collected and the study adhered to the ethical principles of the declaration of Helsinki. ${ }^{27}$ All participants were asked to sign a written consent form prior to the participation. The study and its data collection protocol were reviewed and approved by the Institutional Review Board of AlMaarefa University (Reference number: MCST (AU)-COP 1901/RC). 


\section{Statistical Analyses}

The statistical analyses were conducted using SAS software, version 9.4 (SAS Institute Inc, Cary, NC, USA). Descriptive statistics of the sample at the baseline used means, standard deviations, frequencies, and percentages. The McNemar test was used to compare the results of participants and levels of agreement across different variables.

\section{Results}

\section{Study Participants}

Of the 295 individuals who agreed to take part in the study, $132(44.7 \%)$ were male and $163(55.3 \%)$ were female (Table 1). The mean age of the participants was $33.80 \pm 11.73$ years, and nearly $80 \%$ had a college or postgraduate degree. The median annual income was approximately 20,000 US dollars. The sample consisted of generally healthy individuals, with $33(11.19 \%)$ suffering from GERD, and 23 (7.80\%) and 21 (7.12\%) suffering from hypertension and diabetes, respectively. The mean number of prescription medications taken by the participants was $0.12 \pm 0.36$. The SILS test indicated that the majority of participants $(61.36 \%)$ had adequate health literacy. Eighty-one $(27.46 \%)$ of the study sample were health professionals, $81(27.46 \%)$ reported using herbal supplements, and 238 (80.68\%) indicated having used OTC medications for GERD in the past (Table 1).

\section{Perceptions of DTCA of OTC Medications}

General views of the participants on the DTCA of drugs were obtained before and after watching the DTCA video (Table 2). The presented material did not significantly affect the percentage of participants agreeing or disagreeing with the statement that DTCA is an informative tool in terms of explaining the benefits and harms of drugs (agree or strongly agree: 190 (64.41\%) before vs $213(72.20 \%)$ after viewing the advertisement; disagree or strongly disagree: 47 (15.93\%) before vs 30 (10.17\%) after viewing the advertisement, $P=0.229$ ). In contrast, watching the advertisement increased the percentage of participants agreeing with the statement that DTCA is a credible source of information on OTC drugs (agree or strongly agree: 146 (49.49\%) before vs 191 (64.74\%) after viewing the advertisement; disagree or strongly disagree: $72(24.40 \%)$ before vs 49 (16.61\%) after viewing the advertisement, $P=0.0002$ ). The presentation also increased the level of consent that an attractive and eye-catching DTCA may encourage the participant to purchase the marketed OTC drug (agree or
Table I Baseline Characteristics of Participants

\begin{tabular}{|c|c|}
\hline Characteristic & $\begin{array}{l}\text { Number of } \\
\text { Patients } \\
(n=295)\end{array}$ \\
\hline \multicolumn{2}{|l|}{ Gender } \\
\hline Male, n (\%) & I $32(44.70)$ \\
\hline Female, n (\%) & $163(55.30)$ \\
\hline Age, years; mean $\pm S D$ & $30.80 \pm 11.73$ \\
\hline \multicolumn{2}{|l|}{ Education } \\
\hline No formal education, $\mathrm{n}(\%)$ & $2(0.68)$ \\
\hline Elementary school, n (\%) & $4(1.36)$ \\
\hline Intermediate school, n (\%) & $9(3.05)$ \\
\hline High school, n (\%) & $49(16.61)$ \\
\hline College degree, n (\%) & $210(71.19)$ \\
\hline Postgraduate degree, n (\%) & $21(7.11)$ \\
\hline \multicolumn{2}{|l|}{ Annual income } \\
\hline$<\$ 9600, \mathrm{n}(\%)$ & $128(34.39)$ \\
\hline$\$ 9600-\$ 19,200, n(\%)$ & $40(13.56)$ \\
\hline$\$ 19,200-\$ 28,800, n(\%)$ & $33(11.19)$ \\
\hline$\$ 28,800-\$ 38,400, n(\%)$ & $46(15.59)$ \\
\hline$\$ 38,400-\$ 48,000, \mathrm{n}(\%)$ & $20(6.78)$ \\
\hline$\$ 48,000-\$ 67,200, n(\%)$ & $17(5.76)$ \\
\hline$>\$ 67,200, n(\%)$ & II (3.73) \\
\hline \multicolumn{2}{|l|}{ Medical condition } \\
\hline Diabetes, n (\%) & $21(7.12)$ \\
\hline Hyperlipidemia, n (\%) & $7(2.37)$ \\
\hline Cardiovascular disease, $\mathrm{n}(\%)$ & $4(1.36)$ \\
\hline Ulcer, n (\%) & $14(4.4 .75)$ \\
\hline GERD, n (\%) & $33(11.19)$ \\
\hline Hypertension, n (\%) & $23(7.80)$ \\
\hline Number of Prescription Medications, mean \pm SD & $0.12 \pm 0.36$ \\
\hline \multicolumn{2}{|l|}{ Health literacy } \\
\hline Limited, n (\%) & $114(38.64)$ \\
\hline Adequate, $\mathrm{n}(\%)$ & $|8|(6 \mid .36)$ \\
\hline \multicolumn{2}{|l|}{ Health professional } \\
\hline Yes, n (\%) & $84(28.47)$ \\
\hline No, n (\%) & $211(71.53)$ \\
\hline \multicolumn{2}{|l|}{ Use of herbal supplements } \\
\hline Yes, n (\%) & $81(27.46)$ \\
\hline No, n (\%) & $214(72.54)$ \\
\hline \multicolumn{2}{|l|}{ Use of any OTC drug for GERD } \\
\hline Yes, n (\%) & $238(80.68)$ \\
\hline No, n (\%) & $57(19.32)$ \\
\hline
\end{tabular}

strongly agree: 163 (55.25\%) before vs 210 (71.19\%) after viewing the advertisement; disagree or strongly disagree: $60(20.33 \%)$ before vs 35 (11.86\%) after viewing the advertisement, $P<0.0001)$. However, when asked whether liking 
Table 2 General Perceptions of Direct-to-Consumer Advertisements (DTCA) of Drugs

\begin{tabular}{|c|c|c|c|}
\hline Statement & $\begin{array}{l}\text { Response } \\
\text { Before the } \\
\text { Video, n (\%) }\end{array}$ & $\begin{array}{l}\text { Response } \\
\text { After the } \\
\text { Video, n (\%) }\end{array}$ & $P$-value \\
\hline \multicolumn{4}{|c|}{ I. DTCA is an informing tool about the benefits and harms of drugs. } \\
\hline $\begin{array}{l}\text { (a) Strongly agree } \\
\text { (b) Agree } \\
\text { (c) Neutral } \\
\text { (d) Disagree } \\
\text { (e) Strongly disagree }\end{array}$ & $\begin{array}{l}72(24.41) \\
118(40) \\
58(19.66) \\
10(3.39) \\
37(12.54)\end{array}$ & $\begin{array}{l}80(27.12) \\
133(45.08) \\
52(17.63) \\
7(2.37) \\
23(7.80)\end{array}$ & 0.229 \\
\hline \multicolumn{4}{|c|}{ 2. DTCAs are a credible source of information about OTC drugs. } \\
\hline $\begin{array}{l}\text { (a) Strongly agree } \\
\text { (b) Agree } \\
\text { (c) Neutral } \\
\text { (d) Disagree } \\
\text { (e) Strongly disagree }\end{array}$ & $\begin{array}{l}68(23.05) \\
78(26.44) \\
77(26.10) \\
17(5.76) \\
55(18.64)\end{array}$ & $\begin{array}{l}74(25.08) \\
117(39.66) \\
55(18.64) \\
5(1.69) \\
44(14.92)\end{array}$ & $0.0002 *$ \\
\hline \multicolumn{4}{|c|}{$\begin{array}{l}\text { 3. If the way DTCAs are presented is attractive and catches my eye, it may } \\
\text { encourage me to purchase the marketed OTC drug. }\end{array}$} \\
\hline $\begin{array}{l}\text { (a) Strongly agree } \\
\text { (b) Agree } \\
\text { (c) Neutral } \\
\text { (d) Disagree } \\
\text { (e) Strongly disagree }\end{array}$ & $\begin{array}{l}74(25.08) \\
89(30.17) \\
72(24.41) \\
15(5.08) \\
45(15.25)\end{array}$ & $\begin{array}{l}81(27.46) \\
129(43.73) \\
50(16.95) \\
6(2.03) \\
29(9.83)\end{array}$ & $<0.000$ I* \\
\hline \multicolumn{4}{|c|}{$\begin{array}{l}\text { 4. If I liked a DTCA about a particular OTC drug, this might change my view } \\
\text { about this drug. }\end{array}$} \\
\hline $\begin{array}{l}\text { (a) Strongly agree } \\
\text { (b) Agree } \\
\text { (c) Neutral } \\
\text { (d) Disagree } \\
\text { (e) Strongly disagree }\end{array}$ & $\begin{array}{l}44(14.92) \\
95(32.20) \\
77(26.10) \\
19(6.44) \\
60(20.34)\end{array}$ & $\begin{array}{l}61(20.67) \\
96(3.05) \\
72(24.4 I) \\
9(3.05) \\
57(19.32)\end{array}$ & 0.061 \\
\hline \multicolumn{4}{|c|}{$\begin{array}{l}\text { 5. My decision to buy an OTC drug is independent and is not influenced by } \\
\text { DTCA. }\end{array}$} \\
\hline $\begin{array}{l}\text { (a) Strongly agree } \\
\text { (b) Agree } \\
\text { (c) Neutral } \\
\text { (d) Disagree } \\
\text { (e) Strongly disagree }\end{array}$ & $\begin{array}{l}57(19.32) \\
113(38.31) \\
77(26.10) \\
7(2.37) \\
41(13.89)\end{array}$ & $\begin{array}{l}70(23.73) \\
129(43.73) \\
62(21.02) \\
6(2.03) \\
28(9.49)\end{array}$ & $0.009 *$ \\
\hline \multicolumn{4}{|c|}{$\begin{array}{l}\text { 6. The more frequently I watch DTCAs about a particular pharmaceutical } \\
\text { product, the more likely I will buy that product. }\end{array}$} \\
\hline $\begin{array}{l}\text { (a) Strongly agree } \\
\text { (b) Agree } \\
\text { (c) Neutral } \\
\text { (d) Disagree } \\
\text { (e) Strongly disagree }\end{array}$ & $\begin{array}{l}26(8.8 I) \\
79(26.78) \\
87(29.49) \\
3 I(10.5 I) \\
72(24.4 I)\end{array}$ & $\begin{array}{l}41(13.89) \\
82(27.79) \\
82(27.79) \\
20(6.78) \\
70(23.73)\end{array}$ & 0.061 \\
\hline
\end{tabular}

Note: *Indicates statistically significant difference, $P<0.05$.

a DTCA on a particular OTC drug may change their view about this drug, participants' answers were unaffected by the video (agree or strongly agree: $139(47.12 \%)$ before vs
157 (53.22\%) after viewing the advertisement; disagree or strongly disagree: 79 (26.78\%) before vs $66(22.37 \%)$ after viewing the advertisement, $P=0.061)$. The percentage of participants agreeing with the statement that their decision to buy an OTC drug was independent and not influenced by DTCA increased after watching the video (agree or strongly agree: 170 (57.63\%) before vs 199 (67.46\%) after viewing the advertisement; disagree or strongly disagree: 48 $(16.26 \%)$ before vs $34(11.52 \%)$ after viewing the advertisement, $P=0.009$ ). Finally, the video did not alter the response to the question concerning whether frequent viewing of a DTCA about a particular pharmaceutical product would increase the likelihood of buying that product (agree or strongly agree: 105 (35.59\%) before vs 123 (41.68\%) after viewing the advertisement; disagree or strongly disagree: 103 (34.92\%) before vs 90 (30.51\%) after viewing the advertisement, $P=0.061$ ) (Table 2).

\section{Effect of DTCA on Overall Knowledge of GERD and Its Management}

To determine whether watching the DTCA of OTC medication for GERD had an impact on the participants' understanding of this condition and its management, a three-question multiple-choice quiz was administered before and after viewing the video, as described above. The first question concerned the definition of GERD and was answered correctly by $241(81.69 \%)$ participants before watching the video and by 283 (95.93\%) after watching $(P<0.0001)$ (Table 3$)$. The second question was related to participants' knowledge of OTC medications used in the management of GERD and was answered correctly by 206 (69.83\%) participants before watching the video, and $284(91.27 \%)$ after watching $(P<0.0001)$. The last question addressed participants' awareness of the common side effects of PPIs. Presentation of the video increased the number of correct responses nearly 2-fold, from $137(46.44 \%)$ to $270(91.53 \%) \quad(P<0.0001)$ (Table 3).

\section{Discussion}

This study addressed two aspects of the current debate on the role of DTCA of pharmaceutical products: their perception by potential consumers and the benefit of drug advertising among the general public. A survey of 295 individuals revealed that approximately two-thirds of participants considered DTCA to be an informative tool in terms of explaining the benefits and adverse effects of 
Table 3 The Impact of DTCA on Participants' Knowledge of GERD and Its Management

\begin{tabular}{|l|l|l|l|}
\hline Subject & $\begin{array}{l}\text { The Proportion of } \\
\text { Participants with } \\
\text { Correct Answer Before } \\
\text { the Video, n (\%) }\end{array}$ & $\begin{array}{l}\text { The Proportion of } \\
\text { Participants with } \\
\text { Correct Answer After } \\
\text { the Video, } \mathbf{n}(\%)\end{array}$ & $\begin{array}{l}\text { P-value } \\
\text { the }\end{array}$ \\
\hline $\begin{array}{l}\text { Definition of Gastroesophageal Reflux Disease (GERD). } \\
\text { Knowledge of OTC medications used in the management of GERD. } \\
\text { Awareness of the common side effects of Proton Pump Inhibitors (PPIs) }\end{array}$ & $\begin{array}{l}24 I(8 I .69) \\
206(69.83)\end{array}$ & $\begin{array}{l}283(95.93) \\
284(96.27) \\
270(9 l .53)\end{array}$ & $<0.000 I^{*}$ \\
\hline
\end{tabular}

Note: *Indicates statistically significant difference, $P<0.05$.

drugs, while more than half considered it a credible source. Similarly, approximately half of participants agreed that attractive DTCA may convince them to buy the marketed drug, and may also change their views about a drug. Approximately $60 \%$ of participants stated that their decision to buy an OTC drug was not influenced by DTCA, while only $35 \%$ agreed that frequent watching of DTCA about a particular drug would convince them to purchase it. One of the most important findings, however, was that the perceptions of participants changed significantly after they were presented with the mock DTCA. After viewing, there was an increase in the number of participants who believed that DTCA provides credible information and may encourage the purchase of marketed drugs. In addition, the majority of participants felt that their decision to purchase the drug would be independent of the advertisement. These findings are also in line with previously published studies on the public perceptions of pharmaceutical DTCA. ${ }^{14,15,19}$

Importantly, the content of the video was verified by experts in clinical pharmacy and health outcomes, and was deemed as having a valid educational content. It clearly defined the medical condition to be treated by the medication, explained the different treatment options, identified several specific medications available, provided information on potential adverse effects, and discussed the course of treatment and non-pharmacological recommendations for disease management. Thus, it seems safe to conclude that the advertisement avoided content for which DTCA is frequently criticized, such as biased health information, partial truth about the disease and treatments, inaccurate promises regarding the efficacy of the drug, lack of full disclosure of the risks, and misrepresentation of the prevalence of health conditions. ${ }^{28}$ On the other hand, the video also included elements considered beneficial to the consumers. It increased participants' awareness about the medical condition, educated them about the GERD treatment options, and motivated them to contact their physicians when necessary. ${ }^{29}$ Although it did not fulfill all requirements set forth by the US Code of Federal Regulations Title 21, Section $202,{ }^{30}$ it should be noted that only a small number of broadcasted DTCA is fully compliant with these regulations. ${ }^{31,32}$ More specifically, a recent study suggested that $61 \%$ of the claims in ads for non-prescription drugs were potentially misleading, while $7 \%$ were outright false, refuting the social value of drug advertising. ${ }^{33}$ The data obtained in this study therefore strongly suggest that truthful and fair DTCA of non-prescription drugs could increase public trust in this form of promotion. In contrast, as in the case of the GERD medication Nexium, advertising based on unfair dose comparisons and failure to compare the drug with appropriate alternatives, ultimately reduces public trust, prompting calls for corrections. ${ }^{34}$

The second relevant conclusion is based on the finding that the number of participants providing correct answers to questions related to GERD and its management increased significantly after watching the video. More than $95 \%$ of participants were able to correctly answer questions related to the definition of GERD and medications used to treat this condition. Remarkably, the number of individuals able to name the common side effects of PPIs also increased two-fold, from $137(46.44 \%)$ to $270(91.53 \%)$. These results directly support the claims of proponents of DTCA of pharmaceuticals who state that advertising increases public knowledge of different health conditions and their management. ${ }^{5,18,20,35}$ Importantly, this is the first study to demonstrate this effect of DTCA of GERD medications, which constitute a significant share of the drug advertising market. ${ }^{36}$

Despite its findings, this study had some limitations. For example, convenience sampling was utilized, which might have led to sampling bias. Additionally, the sample size, although it satisfied the pre-established level of statistical power, was relatively small. Moreover, only one example of a carefully designed DTCA was shown to the 
participants, raising the possibility that the outcomes could be different with lower standards, as frequently seen in commercial productions. In addition, watching a motion graphic video to educate the public about a certain class of OTC drugs is sometimes impractical since some people prefer to read about a certain medical condition and the available treatment options rather than watching a video. Furthermore, some people may be skeptical of the content of a video, especially if it involves promotional materials of a specific class of drugs. Despite these limitations, however, novel information has been obtained, highlighting the possibility that DTCA may affect not only public perception of a disease and its treatment options but also attitudes toward this form of promotion.

\section{Conclusions}

Direct-to-consumer advertising of non-prescription drugs is a powerful and useful tool, which if effectively utilized can improve public knowledge of different health conditions that can be managed with OTC medications, while improving sales of the marketed drug. However, ensuring adherence to health regulatory guidelines and regulations, and providing credible and evidence-based information is instrumental in gaining public trust. Overall, the findings of this study highlight the value of pharmaceutical DTCA in improving public knowledge of commonly encountered health conditions and their treatment options.

\section{Abbreviations}

DTCA, Direct to consumer Advertising; FDA, US Food and Drug Administration; GERD, Gastroesophageal Reflux Disease; PPIs, Proton Pump Inhibitors; WHO, World Health Organization; SFDA, Saudi Food and Drug Authority; OTC, Over-the-Counter.

\section{Data Sharing Statement}

Study data are available from the corresponding author (Yazed AlRuthia) upon request.

\section{Acknowledgment}

The authors acknowledge financial support from Researchers Supporting Project number (RSP-2019/16), King Saud University, Riyadh, Saudi Arabia.

\section{Author Contributions}

All authors contributed to data analysis, drafting or revising the article, provided final approval for the version to be published, and agree to be accountable for all aspects of the work.

\section{Disclosure}

The authors report no conflicts of interest in this work.

\section{References}

1. Frank RG, Huskamp HA, Rosenthal MB. Prescription Drug Policy Issues in California. (Report prepared for the California HealthCare Foundation, April 1999).

2. Wilkes MS, Bell RA, Kravitz RL. Direct-to-consumer prescription drug advertising: trends, impact, and implications. Health Aff. 2000;19(2):110-128. doi:10.1377/hlthaff.19.2.110

3. Mansfield PR, Mintzes B, Richards D, Toop L. Direct to consumer advertising. BMJ. 2004;330(7481):5-6. doi:10.1136/bmj.330.7481.5

4. Wang B, Kesselheim AS. The role of direct-to-consumer pharmaceutical advertising in patient consumerism. Virtual Mentor. 2013;15 (11):960-965. doi:10.1001/virtualmentor.2013.15.11.pfor1-1311

5. Gellad ZF, Lyles KW. Direct-to-consumer advertising of pharmaceuticals. Am J Med. 2007;120(6):475-480. doi:10.1016/j.amjmed.2006.09.030

6 . Donohue J. A history of drug advertising: the evolving roles of consumers and consumer protection. Milbank Q. 2006;84(4):659-699. doi:10.1111/milq.2006.84.issue-4

7. Mathur MB, Gould M, Khazeni N. Direct-to-consumer drug advertisements can paradoxically increase intentions to adopt lifestyle changes. Front Psychol. 2016;7:1533. doi:10.3389/fpsyg.2016.01533

8. Mackey TK, Cuomo RE, Liang BA. The rise of digital direct-toconsumer advertising?: comparison of direct-to-consumer advertising expenditure trends from publicly available data sources and global policy implications. BMC Health Serv Res. 2015;15(1):236. doi:10.1186/s12913-015-0885-1

9. Langreth R. Three drug makers, helped by ads, post higher profits Wall Street Journal. 1997 Oct 22.

10. Maguire P. How direct-to-consumer advertising is putting the squeeze on physicians. ACP/ASIM Observer. 1999;1:24-25.

11. Mintzes B, Barer ML, Kravitz RL, et al. How does direct-toconsumer advertising (DTCA) affect prescribing? A survey in primary care environments with and without legal DTCA. CMAJ. 2003;169(5):405-412.

12. Dave D. Direct-to-consumer advertising in pharmaceutical markets: effects on demand and prices. Available from: https://voxeu.org/arti cle/consumer-adverts-pharmaceuticals-impact-prices-and-sales. Accessed December 17, 2019

13. Rosenthal MB, Berndt ER, Donohue JM, et al. Demand effects of recent changes in prescription drug promotion. Forum Health Econ Policy. 2003;6(1):1044. doi:10.2202/1558-9544.1044

14. Gilbody S, Wilson P, Watt I. Benefits and harms of direct to consumer advertising: a systematic review. Qual Saf Health Care. 2005;14(4):246-250. doi:10.1136/qshc.2004.012781

15. Polen HH, Khanfar NM, Clauson KA. Impact of direct-to-consumer advertising (DTCA) on patient health-related behaviors and issues. Health Mark Q. 2009;26(1):42-55. doi:10.1080/07359680802473521

16. Bradford WD, Kleit AN, Nietert PJ, Ornstein S. Effects of direct-toconsumer advertising of hydroxymethylglutaryl coenzyme a reductase inhibitors on attainment of LDL-C goals. Clin Ther. 2006;28 (12):2105-2118. doi:10.1016/j.clinthera.2006.12.015

17. Calfee J, Winston C, Stempski R. Direct-to-consumer advertising and the demand for cholesterol-reducing drugs. J Law Econ. 2002;45 (S2):673-690. doi:10.1086/374704

18. Deshpande A, Menon A, Perri M, Zinkhan G. Direct-to-consumer advertising and its utility in health care decision making: a consumer perspective. J Health Commun. 2004;9:499-513. doi:10.1080/ 10810730490523197

19. Al-Haddad MS, Hamam F, Al-Shakhshir SM. General public knowledge, perceptions and practice towards pharmaceutical drug advertisements in the Western region of KSA. Saudi Pharm J. 2014;22 (2):119-126. doi:10.1016/j.jsps.2013.03.002 
20. Bonaccorso SN, Sturchio JL. For and against. Direct to consumer advertising is medicalising normal human experience. $B M J$. 2002;324(7342):908-911. doi:10.1136/bmj.324.7342.910

21. El-Serag HB, Sweet S, Winchester CC, Dent J. Update on the epidemiology of gastro-oesophageal reflux disease: a systematic review. Gut. 2014;63(6):871-880. doi:10.1136/gutjnl-2012-304269

22. MacFarlane B. Management of gastroesophageal reflux disease in adults: a pharmacist's perspective. Integr Pharm Res Pract. 2018;7:41-52. doi:10.2147/IPRP.S142932

23. Hrelja N, Zerem E. Proton pump inhibitors in the management of gastroesophageal reflux disease. Med Arch. 2011;65:52-55.

24. Savarino V, Di Mario F, Scarpignato C. Proton pump inhibitors in GORD An overview of their pharmacology, efficacy and safety. Pharmacol Res. 2009;59(3):135-153. doi:10.1016/j.phrs.2008.09.016

25. Morris NS, MacLean CD, Chew LD, Littenberg B. The single item literacy screener: evaluation of a brief instrument to identify limited reading ability. BMC Fam Pract. 2006;7(1):21. doi:10.1186/14712296-7-21

26. Al-Jumaili AA, Al-Rekabi MD, Sorofman B. Evaluation of instruments to assess health literacy in Arabic language among Iraqis. Res Social Adm Pharm. 2015;11(6):803-813. doi:10.1016/j.sapharm.2015.02.002

27. World Medical Association. World medical association declaration of Helsinki: ethical principles for medical research involving human subjects. JAMA. 2013;310(20):2191-2194. doi:10.1001/jama.2013.28 1053.

28. Foley L, Gross D. Are consumers well informed about prescription drugs? The impact of printed direct-to-consumer advertising. American Association of Retired Persons; 2010. Available from: https://assets.aarp.org/rgcenter/health/2000_04_advertising.pdf. Accessed December 21, 2019.
29. PhRMA Guiding Principles. Direct to consumer advertisements about prescription medicines; 2018 Available from: https://www.phrma. org/-/media/Project/PhRMA/PhRMA-Org/PhRMA-Org/PDF/ PhRMA_Guiding_Principles_2018.pdf. Accessed December 21, 2019.

30. U.S. Food and Drug Administration. Code of federal regulations title 21; 2019. Available from: https://www.accessdata.fda.gov/scripts/ cdrh/cfdocs/cfcfr/CFRSearch.cfm?fr=202.1. Accessed December 22, 2019.

31. Klara K, Kim J, Ross JS. Direct-to-consumer broadcast advertisements for pharmaceuticals: off-label promotion and adherence to FDA guidelines. $J$ Gen Intern Med. 2018;33(5):651-658. doi:10.1007/s11606-017-4274-9

32. Korenstein D, Keyhani S, Mendelson A, Ross JS, Thiem U. Adherence of pharmaceutical advertisements in medical journals to FDA guidelines and content for safe prescribing. PLoS One. 2011;6 (8):e23336. doi:10.1371/journal.pone.0023336

33. Faerber AE, Kreling DH. Content analysis of false and misleading claims in television advertising for prescription and nonprescription drugs. J Gen Intern Med. 2014;29(1):110-118. doi:10.1007/s11606013-2604-0

34. Sweet M. Website launched to expose "tricks" of drug ads. BMJ. 2003;327(7420):936. doi:10.1136/bmj.327.7420.936

35. Hwang MJ, Young HN. Enhancing the educational value of direct-toconsumer advertising of prescription drugs. $J$ Am Pharm Assoc. 2003;57(5):571-578. doi:10.1016/j.japh.2017.05.008

36. Donohue JM, Cevasco M, Rosenthal MB. A decade of direct-toconsumer advertising of prescription drugs. $N$ Engl J Med. 2007;357(7):673-681. doi:10.1056/NEJMsa070502
Patient Preference and Adherence

\section{Publish your work in this journal}

Patient Preference and Adherence is an international, peer-reviewed, open access journal that focuses on the growing importance of patient preference and adherence throughout the therapeutic continuum. Patient satisfaction, acceptability, quality of life, compliance, persistence and their role in developing new therapeutic modalities and compounds to optimize clinical outcomes for existing disease states are major areas of interest for the journal. This journal has been accepted for indexing on PubMed Central. The manuscript management system is completely online and includes a very quick and fair peer-review system, which is all easy to use. Visit http:// www.dovepress.com/testimonials.php to read real quotes from published authors. 